Check for updates

Cite this: RSC Adv., 2018, 8, 4766

Received 8th November 2017 Accepted 11th January 2018

DOI: $10.1039 / c 7 r a 12252 g$

rsc.li/rsc-advances

\section{A dual-emission nano-rod MOF equipped with carbon dots for visual detection of doxycycline and sensitive sensing of $\mathrm{MnO}_{4}^{-} \dagger$}

\begin{abstract}
Xin Fu, Rui Lv, Jian Su, Hui Li, Boyi Yang, Wen Gu* and Xin Liu (DD *
Herein, ethanediamine-modified carbon dots (CDs) were encapsulated into luminescent MOF(Eu), which was designed for a dual-emission hybrid material (CDs@MOF(Eu)) with diverse fluorescence applications. This material exhibited high selectivity and sensitivity towards doxycycline. With an increasing concentration of doxycycline, the blue light emission of CDs could be quenched, whereas the red light emission of MOF(Eu) was enhanced. In view of this result, more convenient "test paper" was used first as a new tool for doxycycline detection, the colour of which turned from blue-purple to red as observed by the naked eyes under $365 \mathrm{~nm}$ UV-irradiation. This hybrid material also was a probe for sensing $\mathrm{MnO}_{4}{ }^{-}$ with a low limit of detection and good anti-interference performance. We propose that CDs can improve detection sensitivity compared with the original MOF(Eu). The possible sensing mechanism was discussed in detail. Importantly, the feasibility of this composite for sensing doxycycline in a simulated biological system and sensing $\mathrm{MnO}_{4}{ }^{-}$in tap water was investigated.
\end{abstract}

\section{Introduction}

At present, the abuse of antibiotics is becoming more common. Doxycycline is a tetracycline compound that can be used to treat infections of the respiratory, urinary, and biliary tracts caused by sensitive bacteria. ${ }^{1}$ Doxycycline can also prevent falciparum malaria and leptospirosis infection, and is often used as a veterinary drug in animal breeding. However, the residue of doxycycline in water-based environments and everyday foods has several side effects, such as hepatotoxicity, yellow teeth, gastrointestinal symptoms and mentation changes, especially in children; in addition, doxycycline use can lead to antibiotic resistance. ${ }^{2,3}$ Numerous test methods have been developed to detect tetracycline antibiotics: electrochemical analysis, ${ }^{4,5} \mathrm{UV}$ absorbance spectroscopy (UV-vis), ${ }^{6,7}$ liquid chromatography, ${ }^{8-10}$ flow-injection analysis, ${ }^{11,12}$ and fluorescence spectrophotometry. ${ }^{13,14}$ Fluorescence spectrophotometry stands out among these methods because it is sensitive, fast and cost-effective. Currently, "test paper" based on fluorescence spectrophotometry has become popular in molecular detection because it is convenient, inexpensive and easy to carry out. However, few studies on antibiotic detection using test paper have been

College of Chemistry, Key Laboratory of Advanced Energy Materials Chemistry (MOE), Tianjin Key Laboratory of Metal and Molecule Based Material Chemistry, Collaborative Innovation Center of Chemical Science and Engineering, Nankai University, Tianjin 300071, P. R. China. E-mail: liuxin64@nankai.edu.cn; guwen68@nankai.edu.cn

$\dagger$ Electronic supplementary information (ESI) available. See DOI: $10.1039 / \mathrm{c} 7 \mathrm{ra12252g}$ undertaken. Several materials have been used for doxycycline detection based on fluorescence spectrophotometry, especially quantum dots..$^{15}$ During recent years, quantum-dot materials have been used in various applications that have advantages such as nanometre size, simple synthesis method, low toxicity and high quantum yield. ${ }^{16-18}$ Carbon dots (CDs) are a novel form of quantum dots. CDs have been applied to detect many metal ions, ${ }^{19-22}$ pollutants, ${ }^{23-25}$ biomolecules ${ }^{26}$ and antibiotics ${ }^{27}$ with high fluorescence selectivity and sensitivity.

Luminescent lanthanide metal organic frameworks (Ln-MOFs) are a class of crystalline materials that have attracted much attention in recent years. Ln-MOFs have large specific surface areas, adjustable pore sizes, unsaturated metal coordination sites, and good fluorescence of rare earth metal ions. Thus, several applications have been based on the advantages stated above, such as fluorescence probes for detection. ${ }^{28-30}$ If CDs are incorporated with MOFs, the formed hybrid materials would have enhanced fluorescence properties. If the MOFs have no fluorescence, dual-emission fluorescence could be obtained by doping rare earth ions, whereas MOFs could act as a "box" for loading CDs and rare earth ions. For instance, Dong et al. used Eu-MOFs encapsulating blue emission N,S-CDs to form a dualemission material for visual detection of water in organic solvents. This material showed red light emission in organic solvents and blue light emission in water. ${ }^{31} \mathrm{Xu}$ et al. synthesized MOF-253 encapsulating $\mathrm{CDs}$ and $\mathrm{Eu}^{3+}$. The prepared fluorescent probe can detect $\mathrm{Hg}^{2+}$ in aqueous solution with a limit of detection (LOD) of $13 \mathrm{ppb}$. $\mathrm{Hg}^{2+}$ only quenched the fluorescence of CDs; the red emission of $\mathrm{Eu}^{3+}$ was not affected. Also, the 
colour of this probe changed significantly under UV irradiation..$^{32}$

Potassium permanganate $\left(\mathrm{KMnO}_{4}\right)$ is a strong oxidant and often serves as an antiseptic and disinfectant. $\mathrm{KMnO}_{4}$ is also applied for treating fish diseases and polluted water. ${ }^{33}$ However, it is toxic, corrosive and harmful to human health, and can lead to respiratory infections and skin irritation. ${ }^{34}$ Hence, the precise detection of $\mathrm{MnO}_{4}{ }^{-}$has become a major component of waterpollution detection for environmental evaluation.

In this work, we report a bifunctional hybrid material CDs@MOF(Eu) that can detect doxycycline and $\mathrm{MnO}_{4}{ }^{-}$. This composite was synthetized through a simple method that induced blue light emission CDs into $\mathrm{MOF}(\mathrm{Eu})$. The ratio of two fluorescence peaks $\left(F_{616 \mathrm{~nm}} / F_{436 \mathrm{~nm}}\right)$ exhibited excellent sensitivity and selectivity for doxycycline. Also, detection was possible with the naked eyes using test paper under UV irradiation of $365 \mathrm{~nm}$. Compared with other materials, this hybrid material based on the fluorescence ratio of two peaks could reduce interference from the environment and minimize the drift value of the instrument, thereby making the results reliable. ${ }^{35}$ Also, the two emissions may result in colour changes in the presence of doxycycline, which makes visual detection easier than that for single-emission materials. Besides, the composite could also be applied to $\mathrm{MnO}_{4}{ }^{-}$detection for instruments with a low LOD; CDs accelerated the speed of the detection and made the LOD lower compared with that of the original $\mathrm{MOF}(\mathrm{Eu})$. More importantly, this sensor also exhibited very promising applications for sensing doxycycline in simulated biological systems and for detecting $\mathrm{MnO}_{4}{ }^{-}$in tap water.

\section{Experimental}

\section{Materials}

Citric acid, ethylenediamine, 1,3,5-benzenetricarboxylic acid $\left(\mathrm{H}_{3} \mathrm{BTC}\right)$, europium nitrate hexahydrate $\left(\mathrm{Eu}\left(\mathrm{NO}_{3}\right)_{3} \cdot 6 \mathrm{H}_{2} \mathrm{O}\right)$, tris(hydroxymethyl)aminomethane (Tris), DMF, ethanol, $\mathrm{HCl}$, chlorotetracycline, doxycycline, isoniazid, oxytetracycline, neomycin, kanamycin, metronidazole, chloramphenicol, erythromycin, tetracycline, phenylalanine (Phe), valine (Val), cysteine (Cys), glutathione (GSH), aspartic acid (Asp), glycine (Gly), $\mathrm{KNO}_{3}, \mathrm{NaNO}_{3}, \mathrm{Zn}\left(\mathrm{NO}_{3}\right)_{2} \cdot 6 \mathrm{H}_{2} \mathrm{O}, \mathrm{Ca}\left(\mathrm{NO}_{3}\right)_{2}, \mathrm{KMnO}_{4}, \mathrm{CH}_{3^{-}}$ COOK, $\mathrm{K}_{2} \mathrm{CO}_{3}, \mathrm{KClO}_{3}, \mathrm{~K}_{2} \mathrm{C}_{2} \mathrm{O}_{4}, \mathrm{~K}_{2} \mathrm{SO}_{3}, \mathrm{KHCO}_{3}, \mathrm{NaNO}_{2}$ and $\mathrm{NaH}_{2} \mathrm{PO}_{2} \cdot \mathrm{H}_{2} \mathrm{O}$ were of analytical grade and used without further purification. Ultra-pure grade water $(18.2 \mathrm{M} \Omega)$ was used as the solvent in all experiments.

\section{Apparatus}

Transmission electron microscopy (TEM) was undertaken using an FEI Tecnai G2 S-Twin transmission electron microscope. Scanning electron microscopy (SEM) was done using a JEOL JSM$7500 \mathrm{~F}$ field emission scanning electron microscope. Energydispersive X-ray spectroscopy (EDS) was done on a Merlin Compact scanning electron microscope. X-ray diffraction (XRD) patterns were measured on D8 Focus diffractometer with $\mathrm{Cu}-\mathrm{K} \alpha$ radiation $(\lambda=0.15405 \mathrm{~nm})$. Fourier transform infrared (FTIR) spectroscopy was undertaken on a Bruker Tensor 27 FTIR spectrometer using $\mathrm{KBr}$ pellets. All fluorescence spectra were recorded on a FLS 920P Edinburgh instrument. $\mathrm{N}_{2}$ adsorptiondesorption was measured on a Micromeritics ASAP 2020 HD88 apparatus. UV-vis spectra were recorded on a Shimadzu UV-3600 spectrometer. X-ray photoelectron spectroscopy (XPS) was carried out on an Axis Ultra DLD X-ray photoelectron spectrometer.

\section{Synthesis of CDs}

CDs were synthesized according to a simple method. In brief, citric acid $(1.0507 \mathrm{~g})$ was added into $10 \mathrm{~mL}$ ultra-pure water and dissolved completely. Then, $335 \mu \mathrm{L}$ ethylene diamine was injected quickly into the solution, the mixture transferred into a $25 \mathrm{~mL}$ Teflon ${ }^{\mathrm{TM}}$-lined autoclave, and maintained for $5 \mathrm{~h}$ at $200{ }^{\circ} \mathrm{C}$. Finally, a dark-brown solution was obtained, filtered using a membrane, and placed in darkness for further use.

\section{Synthesis of CDs@MOF(Eu)}

The synthetic method of $\mathrm{MOF}(\mathrm{Eu})$ has been described. ${ }^{36}$ First, a water solution of CDs was prepared with a proportion of $V_{\mathrm{CDs}}: V_{\text {water }}=1: 10$ (the amount of CDs in each reaction kettle was $\left.6.56 \times 10^{-4} \mathrm{~mol}\right)$. Typically, $\mathrm{Eu}\left(\mathrm{NO}_{3}\right)_{3} \cdot 6 \mathrm{H}_{2} \mathrm{O}(0.00331 \mathrm{~g})$ and $\mathrm{H}_{3} \mathrm{BTC}(0.0156 \mathrm{~g})$ were added into a mixed solution containing $3 \mathrm{~mL}$ DMF and $3 \mathrm{~mL}$ ethanol. Then, $2 \mathrm{~mL}$ prepared CDs in water solution was injected into the mixture and sonicated for $5 \mathrm{~min}$. The mixture was transferred to a $25 \mathrm{~mL}$ Teflon-lined autoclave and maintained for $24 \mathrm{~h}$ at $80^{\circ} \mathrm{C}$. A light-brown solid were obtained by centrifugation for $5 \mathrm{~min}$ at $8000 \mathrm{rpm}$. The precipitate was washed thrice with DMF and water. Then, the sample was immersed in methanol and $\mathrm{CH}_{2} \mathrm{Cl}_{2}$ for $12 \mathrm{~h}$, respectively. Samples were obtained by centrifugation and then dried $12 \mathrm{~h}$ at $50{ }^{\circ} \mathrm{C}$.

\section{Detection of fluorescence and test paper}

Initially, the concentration of tested molecule solutions was $10^{-2} \mathrm{M}$. The sample solutions to be tested were prepared in $0.05 \mathrm{M}$ Tris- $\mathrm{HCl}$ buffered solution (pH 7.3). Then, $1 \mathrm{mg}$ CDs@MOF(Eu)was dispersed into $5 \mathrm{~mL}$ buffered solution and sonicated for $5 \mathrm{~min}$ to obtain a well-dispersed suspension which was used for luminescence experiments. For sensing doxycycline in real samples, Tris-buffered saline $(0.1 \mathrm{M}$ Tris-HClbuffered solution containing $0.015 \mathrm{~mol} \mathrm{NaCl}, \mathrm{pH}$ 7.4) was chosen as a simulated biological system. All selectivity and antiinterference experiments were done by adding $100 \mu \mathrm{L}$ analyte into the sample solution, and shaking thoroughly before detection. The test paper was made from filter paper and cut into rectangles. When detecting doxycycline, the test paper was soaked into sample solutions containing different concentrations of doxycycline for $2 \mathrm{~min}$. Then, the test paper was clipped with tweezers and left to dry naturally in air. Photographs of test papers were taken in a dark box under UV irradiation at $365 \mathrm{~nm}$.

\section{Results and discussion}

\section{Characterization}

The morphology of the composites was confirmed by TEM and SEM. Fig. 1a and $b$ shows the images of CDs, which were 

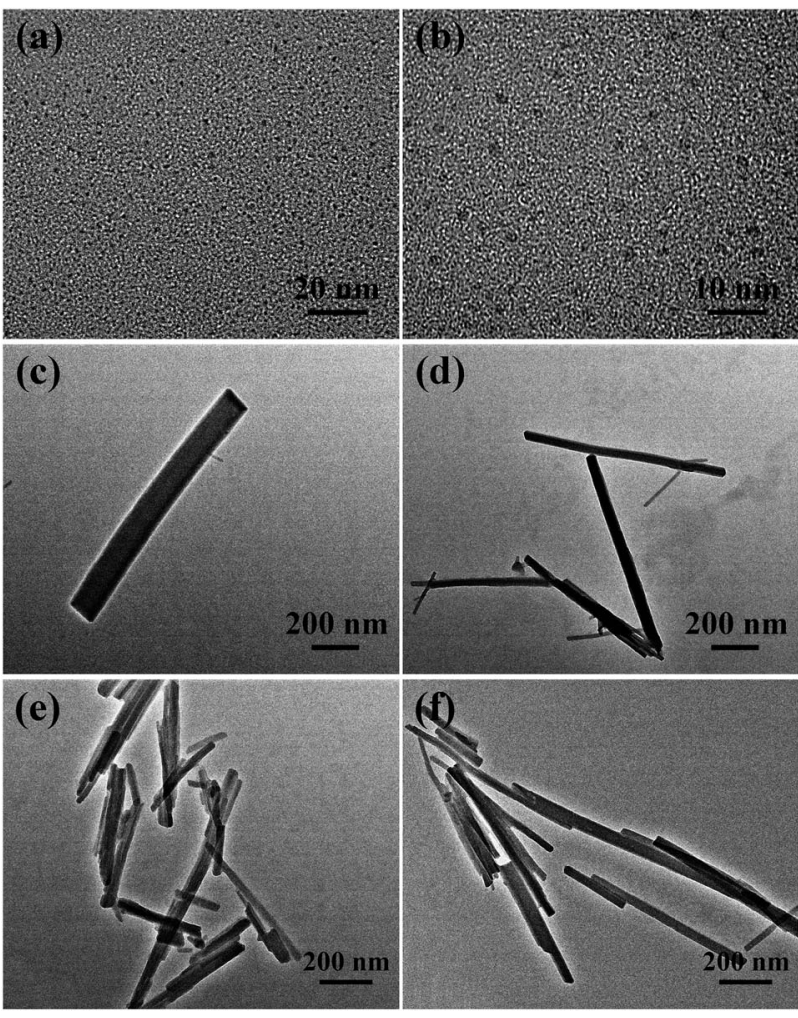

Fig. 1 Transmission electron micrographs of carbon dots ( $a$ and $b$ ), CDs@MOF(Eu) (c and d) and MOF(Eu) (e and f).

spherical and of size $\approx 2 \mathrm{~nm}$. The composite and $\mathrm{MOF}(\mathrm{Eu})$ were all rod-like and of the same size (Fig. 1c-f, S1a and b†). The microstructure morphology of the composite is shown in Fig. S2. $\dagger$ The surface of the rod was smooth, which suggested that the added CDs were not attached to the surface of the MOFs. By virtue of their structure, the strong peaks of $\operatorname{MOF}(\mathrm{Eu})$ were not destroyed in the XRD pattern after combination with CDs (Fig. 2a). It was difficult to observe CDs in the TEM images of the composite (Fig. 2b) but a typical type-I isotherm of MOF was obtained. Also, a sharp decrease of the Brunauer-Emmett-Teller surface area from $102.8699 \mathrm{~m}^{2} \mathrm{~g}^{-1}$ to $10.9979 \mathrm{~m}^{2} \mathrm{~g}^{-1}$ demonstrated that CDs were encapsulated into $\mathrm{MOF}(\mathrm{Eu})$. FTIR spectra were also used to confirm the main groups in the composite (Fig. S3†). A broad peak at $3396 \mathrm{~cm}^{-1}$ was assigned to an O-H stretching vibration, and a sharp peak at $1614 \mathrm{~cm}^{-1}$ was from the
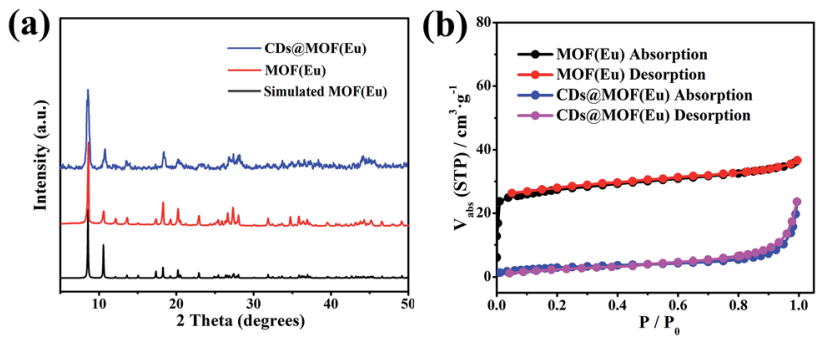

Fig. 2 (a) Comparison of the XRD patterns of $M O F(E u)$ and CDs@MOF(Eu) composite. (b) $\mathrm{N}_{2}$ absorption-desorption isotherms of $\mathrm{MOF}(\mathrm{Eu})$ and CDs@MOF(Eu). bending vibration of $\mathrm{N}-\mathrm{H}$. The band at $1114 \mathrm{~cm}^{-1}$ was attributed to $\mathrm{C}-\mathrm{N}$ stretching vibrations, and the bands at $771 \mathrm{~cm}^{-1}$ and $726 \mathrm{~cm}^{-1}$ were from an $\mathrm{N}-\mathrm{H}$ wagging vibration. These results indicated the functional groups in the composite and induced CDs did not destroy the structure of the complex.

\section{Detection and sensing mechanism of doxycycline}

The property of sensing antibiotics was observed. As shown in Fig. 3a, the fluorescence intensity at $616 \mathrm{~nm}$ increased with the addition of doxycycline, conversely, the fluorescence intensity at $436 \mathrm{~nm}$ decreased. Meanwhile, the value of $\ln \left(F_{616 \mathrm{~nm}} / F_{436} \mathrm{~nm}\right)$ had a good linear relationship with doxycycline concentration with an adjusted $R^{2}$ of 0.99401 (Fig. 3b). The LOD $(3 \sigma / s)$ was calculated to be $0.36 \mu \mathrm{M}$, which was better than the other methods stated in the literature (Table S1 $\dagger$ ). Fig. $3 \mathrm{c}$ shows the subtle colour changes of the test paper under a $365 \mathrm{~nm}$ UV lamp upon doxycycline addition; the colour changed from blue-purple to pink-red as the concentration of doxycycline increased $(0-200 \mu \mathrm{M})$. Different categories of antibiotics were selected to investigate selectivity under identical conditions. $\ln \left(F_{616 \mathrm{~nm}} / F_{436} \mathrm{~nm}\right)$ showed no obvious change for other antibiotics, which demonstrated that doxycycline could be identified readily from other antibiotics (Fig. $4 \mathrm{a}$ and $\mathrm{b}$ ). With respect to anti-interference ability, the $\ln \left(F_{616} \mathrm{~nm} / F_{436} \mathrm{~nm}\right)$ of the composite showed no obvious change in the presence of other interfering substances (Fig. 4c). Three other tetracycline antibiotics were also studied (Fig. S4†); although they had similar structures, the value of $\ln \left(F_{616 \mathrm{~nm}} / F_{436 \mathrm{~nm}}\right)$ of doxycycline was more obvious.

Electronic absorption spectra (UV-vis) were used to analyse the possible sensing mechanism of doxycycline. As depicted in Fig. $4 \mathrm{~d}$, the overlaps between the absorption peak of doxycycline and emission peak of the CDs indicated that energy transfer might occur, resulting in the fluorescence quenching of CDs on the basis of the Förster resonance energy transfer mechanism. Inspired by the studies carried out by Jiang et al., ${ }^{37-39}$ doxycycline was an ideal ligand for $\mathrm{Eu}^{3+}$ that could form a doxycycline$\mathrm{Eu}^{3+}$ complex and enhance the fluorescence of $\mathrm{Eu}^{3+}$. Hence, the integration of doxycycline and $\mathrm{Eu}^{3+}$ may cause the fluorescence enhancement of the emission peak at $616 \mathrm{~nm}$. Accordingly, the spectrum showed a fall and rise simultaneously in the presence of doxycycline.

\section{$\mathrm{MnO}_{4}{ }^{-}$detection and possible sensing mechanism}

The effects of different anions $\left(\mathrm{MnO}_{4}{ }^{-}, \mathrm{NO}_{3}{ }^{-}, \mathrm{CH}_{3} \mathrm{COO}^{-}, \mathrm{CO}_{3}{ }^{2-}\right.$, $\mathrm{ClO}_{3}{ }^{-}, \mathrm{C}_{2} \mathrm{O}_{4}{ }^{2-}, \mathrm{SO}_{3}{ }^{2-}, \mathrm{HCO}_{3}{ }^{-}, \mathrm{NO}_{2}{ }^{-}, \mathrm{H}_{2} \mathrm{PO}_{2}{ }^{-}$) on the composites were studied. The fluorescence intensity at $616 \mathrm{~nm}$ was quenched upon addition of $\mathrm{MnO}_{4}^{-}$(Fig. 5a). An experiment using original $\operatorname{MOF}(\mathrm{Eu})$ without CDs was also investigated. As shown in Fig. S5, $\dagger$ the fluorescence of original MOF(Eu) showed no obvious change as the $\mathrm{MnO}_{4}{ }^{-}$concentration increased. Conversely, the $616 \mathrm{~nm}$ fluorescence of the composite was quenched by $\approx 50 \%$ at the same concentration of $\mathrm{MnO}_{4}{ }^{-}$and the corresponding quenching constant was calculated: it was $3.641 \times 10^{4} \mathrm{~L} \mathrm{~mol}^{-1}$ (Fig. 5b). This observation suggested that CDs probably accelerated this process, and lowered the $\mathrm{LoD}$ (from $12.43 \mu \mathrm{M}$ to 0.68 $\mu \mathrm{M})$. This sensor had good selectivity towards $\mathrm{MnO}_{4}{ }^{-}$and the 

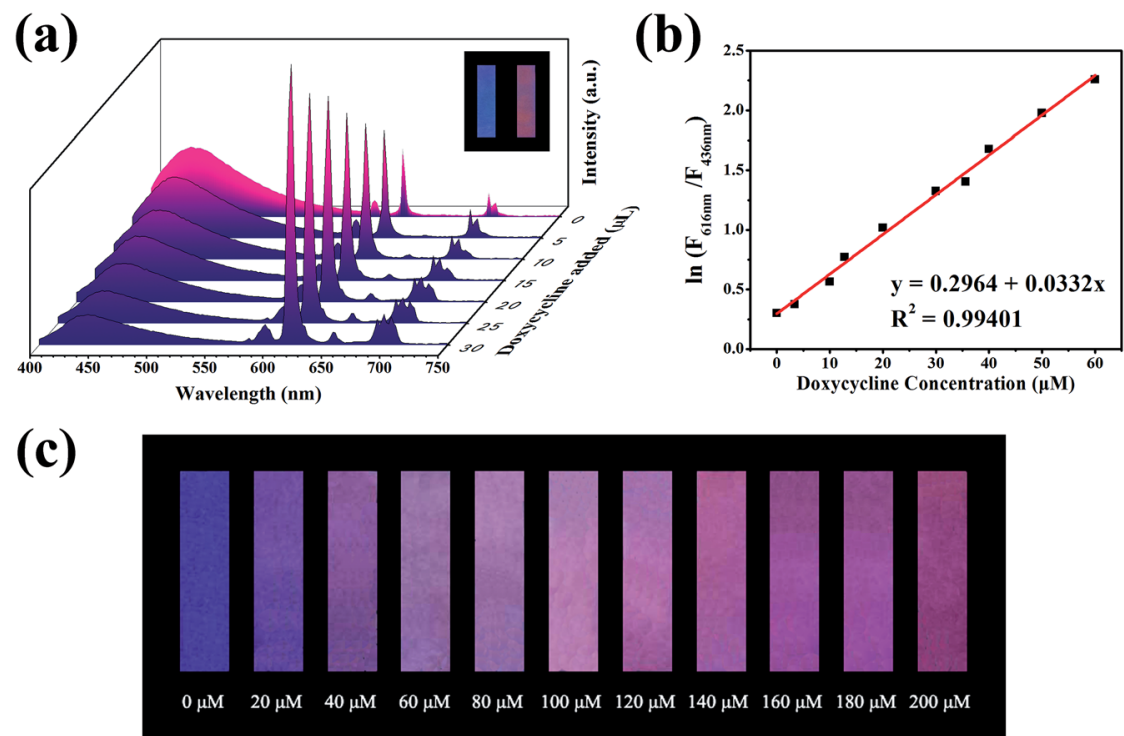

Fig. 3 (a) Fluorescence spectra of composites with different concentrations of doxycycline under 298 nm excitation. (b) The linear relationship of $\ln \left(F_{616 \mathrm{~nm}} / F_{436 \mathrm{~nm}}\right)$ and concentration of doxycycline. (c) The colour change of "test paper" as the concentration of doxycycline increased under $365 \mathrm{~nm}$ UV irradiation.

quenching process did not suffer interference by other anions (Fig. $5 \mathrm{c}$ and d).

The colour of $\mathrm{KMnO}_{4}$ lightened after detection, indicating that some reactions may have occurred. Characterization methods (SEM, XPS, FT-IR spectroscopy, XRD, UV-vis spectroscopy) were employed to study the possible sensing mechanism. On account of the contrast experiment of $\mathrm{MOF}(\mathrm{Eu})$ mentioned above, we suspected that CDs may react with $\mathrm{MnO}_{4}{ }^{-}$, resulting in acceleration of the quenching progress. The UV spectra of the $\mathrm{CDs} @ \mathrm{MOF}(\mathrm{Eu})-\mathrm{KMnO}_{4}$ hybrid system changed in comparison with previous spectra (Fig. S6†), which suggested that a ground state complex could have been generated. ${ }^{40}$ SEM images and the corresponding element mapping images are given in Fig. S7. $\dagger$ It can be seen clearly that the manganese element is distributed uniformly on the surface of the composite, thereby showing the formation of manganese (a)

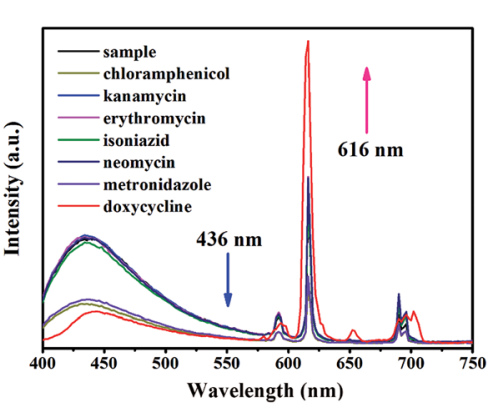

(c)

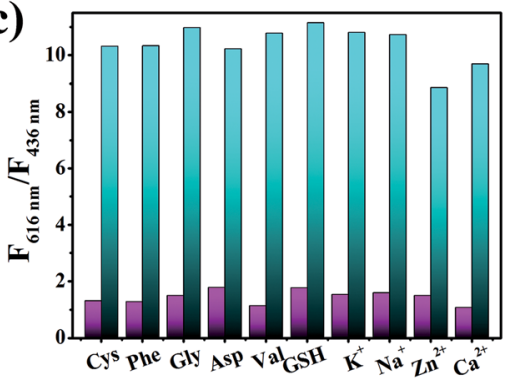

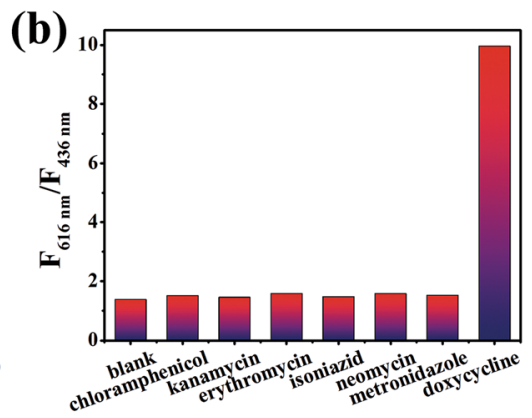

(d)

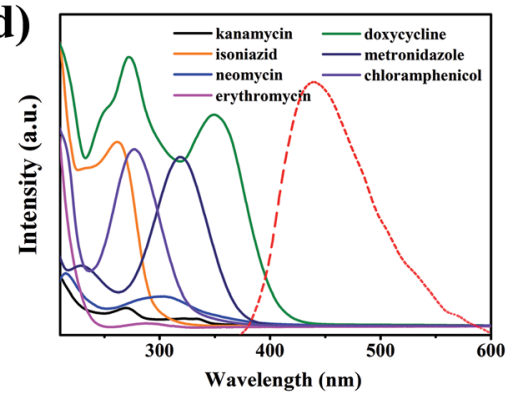

Fig. 4 (a) Fluorescence spectra of composites added with different antibiotics. (b) Selectivity of doxycycline based on the ratio of $F_{616} \mathrm{~nm}$ and $F_{436 \mathrm{~nm}}$. (c) Value of $F_{616 \mathrm{~nm}} / F_{436} \mathrm{~nm}$ in the presence of other interfering substances (excited at $298 \mathrm{~nm}$ ). (d) Absorption spectrum of different antibiotics and emission spectra of carbon dots. 
(a)

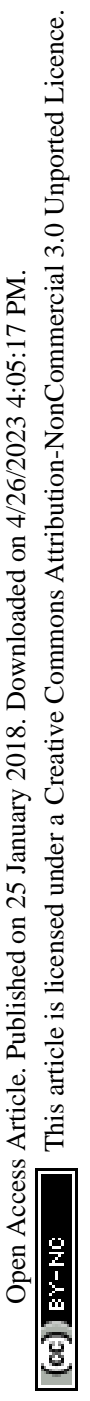

(c)

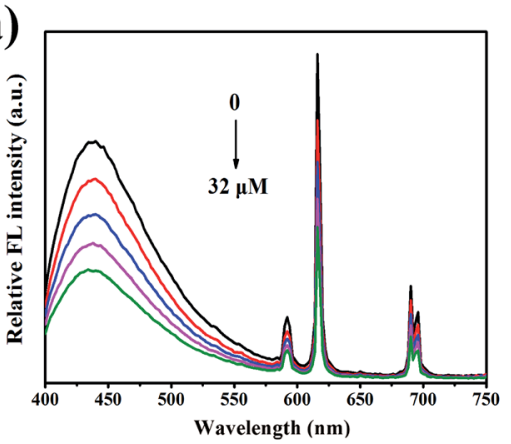

(b)
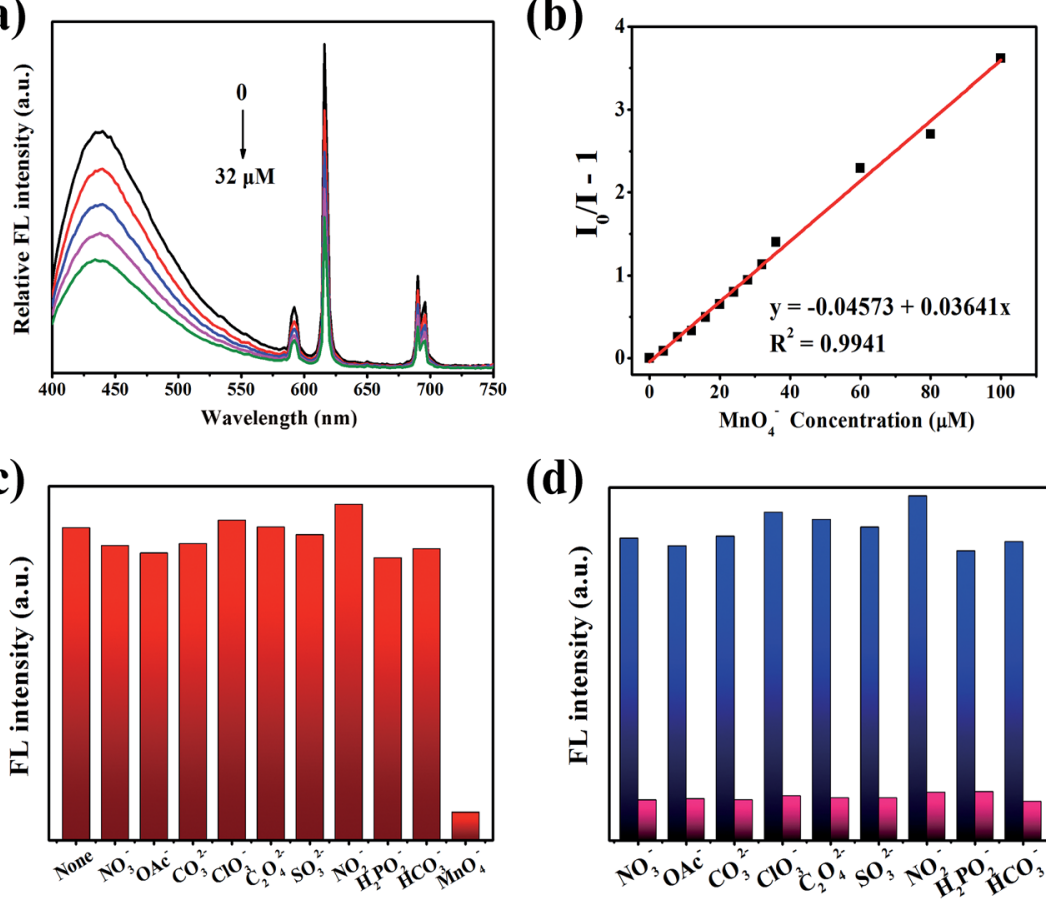

(d)

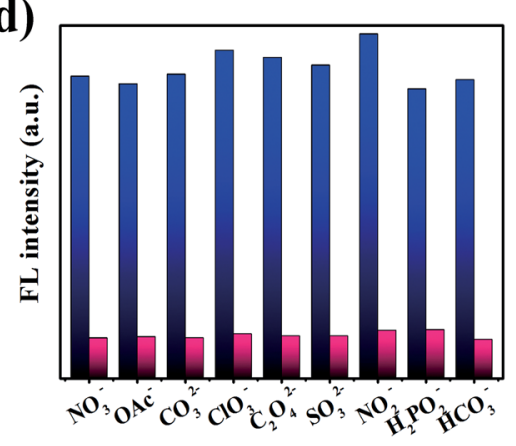

Fig. 5 (a) Emission spectra of $\mathrm{CDs}\left(\mathrm{MOF}(\mathrm{Eu})\right.$ with added $\mathrm{MnO}_{4}{ }^{-}(0-32 \mu \mathrm{M})$. (b) The linear relationship between $\mathrm{MnO}_{4}{ }^{-}$concentration and $I_{0} / /-1$ based on the $616 \mathrm{~nm}$ emission peak. (c) The selectivity of $\mathrm{MnO}_{4}{ }^{-}$with that of other anions. (d) Fluorescence intensity at $616 \mathrm{~nm}$ of composites with added $\mathrm{MnO}_{4}{ }^{-}(0.2 \mathrm{mM})$ in the interference of other anions $(0.2 \mathrm{mM})$.

compounds. XPS was done to judge the valence of the manganese element in compounds. As shown in Fig. S8a, $\uparrow$ the peaks of C1s (282 eV), O1s (529 eV), N1s (397 eV), Eu4d (134 eV) and Mn2p (639 eV) appeared in the broad spectrum, demonstrating the main elements and contents in the CDs@MO$\mathrm{F}(\mathrm{Eu})-\mathrm{KMnO}_{4}$ hybrid system. The content of manganese was relatively small, so it was not obviously displayed in the broad spectrum. In the C1s spectrum, the three peaks at 284.5, 286, and $288.2 \mathrm{eV}$ were assigned to $\mathrm{C}-\mathrm{C}$ or $\mathrm{C}=\mathrm{C}, \mathrm{C}-\mathrm{N}, \mathrm{N}-\mathrm{C}=\mathrm{O}$ peaks (Fig. S8b†). The two peaks at 531.2 and $532.5 \mathrm{eV}$ in the $\mathrm{O} 1 \mathrm{~s}$ spectrum corresponded to $\mathrm{O}=\mathrm{C}$ and $\mathrm{O}-\mathrm{C}$ peaks (Fig. S8c $\dagger$ ). The two peaks at 399.5 and $401.4 \mathrm{eV}$ in the N1s spectrum belonged to $\mathrm{C}-\mathrm{N}-\mathrm{C}$ and $\mathrm{N}-\mathrm{H}$ peaks (Fig. $\mathrm{S} 8 \mathrm{~d} \dagger$ ). In the Mn2p spectrum (Fig. S8e $\dagger$ ), the two peaks at 641.4 and $653.1 \mathrm{eV}$ were attributed to $M n 2 \mathrm{p}_{3 / 2}$ and $M n 2 \mathrm{p}_{1 / 2}$, respectively. Their spin energy separation was $11.7 \mathrm{eV}$, illustrating that $\mathrm{MnO}_{2}$ could exist in the hybrid system, a result that was in good agreement with the literature. ${ }^{41,42}$ Hence, we proposed two possible explanations for the sensing mechanism. First, the quenching of $616 \mathrm{~nm}$ fluorescence could be explained in terms of energy. As shown in Fig. S9, $\uparrow$ an overlap was present between the excitation of the composite and the absorption of $\mathrm{MnO}_{4}{ }^{-}$. The competition in energy of excitation and adsorption between $\mathrm{MOF}(\mathrm{Eu})$ and $\mathrm{MnO}_{4}{ }^{-}$could lead to fluorescence quenching, ${ }^{43}$ and CDs may accelerate the progress of energy competition. The XRD patterns in Fig. S10† suggested another possible sensing mechanism. $\mathrm{MnO}_{4}{ }^{-}$may have weak interactions with the framework of $\mathrm{MOF}(\mathrm{Eu})$. Meanwhile, $\mathrm{MnO}_{4}{ }^{-}$ reacted with some CDs initially, resulting in the formation of
$\mathrm{MnO}_{2}$, which could accelerate the interaction between $\mathrm{MnO}_{4}{ }^{-}$ and $\operatorname{MOF}(\mathrm{Eu})$. Otherwise, this sensor was comparable with other MOFs for sensing $\mathrm{MnO}_{4}{ }^{-}$, and the addition of CDs made the performance of $\mathrm{MOF}(\mathrm{Eu})$ almost identical or even better than that of similar materials (Table S2 $\dagger$ ).

\section{Applications in real samples}

Doxycycline is often used to treat people or animals. Hence, TBS buffer solution was used to simulate a biological environment to detect doxycycline. $\mathrm{MnO}_{4}{ }^{-}$is known to be a common pollutant, so accurate quantitative determination of $\mathrm{MnO}_{4}{ }^{-}$in tap water is very important. As shown in Tables 1 and 2, the relative standard deviation of the results was $<3 \%$, indicating that these data were reliable. The measured concentration was calculated according to the previous linear equations $\left(C: \mathrm{mol} \mathrm{L}^{-1}\right)$ :

$$
\ln \left(F_{616 \mathrm{~nm}} / F_{436 \mathrm{~nm}}\right)=0.2964+0.0332 \times C_{\text {dox }}
$$

Table 1 Analytical results of doxycycline detection in a simulated biological system (TBS)

\begin{tabular}{lllll}
\hline Sample & $\begin{array}{l}\text { Spiked } \\
\text { concentration }(\mu \mathrm{M})\end{array}$ & $\begin{array}{l}\text { Measure } \\
(\mu \mathrm{M})\end{array}$ & $\begin{array}{l}\text { Recovery } \\
(\%)\end{array}$ & $\begin{array}{l}\text { RSD (\%), } \\
n=3\end{array}$ \\
\hline 1 & 15.8 & 14.85 & 93.95 & 0.70 \\
2 & 27 & 27.08 & 100.31 & 1.41 \\
3 & 35.6 & 36.41 & 102.28 & 1.29 \\
4 & 44.2 & 44.36 & 100.37 & 0.66 \\
5 & 56.6 & 54.44 & 96.19 & 0.54
\end{tabular}


Table 2 Analytical results of $\mathrm{MnO}_{4}{ }^{-}$detection in tap water

\begin{tabular}{lllll}
\hline Sample & $\begin{array}{l}\text { Spiked } \\
\text { concentration }(\mu \mathrm{M})\end{array}$ & $\begin{array}{l}\text { Measure } \\
(\mu \mathrm{M})\end{array}$ & $\begin{array}{l}\text { Recovery } \\
(\%)\end{array}$ & $\begin{array}{l}\text { RSD }(\%), \\
n=3\end{array}$ \\
\hline 1 & 10.4 & 10.10 & 97.15 & 2.48 \\
2 & 17.6 & 17.71 & 100.61 & 0.92 \\
3 & 29.4 & 29.91 & 101.72 & 2.61 \\
4 & 46.2 & 46.59 & 100.85 & 0.60 \\
5 & 75 & 74.91 & 99.88 & 1.54 \\
\hline
\end{tabular}

$$
F_{0} / F-1=-0.04573+0.03641 \times C_{\mathrm{MnO}_{4}}
$$

Good detection recoveries of doxycycline and $\mathrm{MnO}_{4}{ }^{-}$were acquired (93.95-102.28\%). Such accuracy and reliability further confirmed that this composite was a promising and efficient sensor for the detection of doxycycline and $\mathrm{MnO}_{4}{ }^{-}$in real samples.

\section{Conclusions}

We synthesized a hybrid material which had dual-emission fluorescence for sensing doxycycline and $\mathrm{MnO}_{4}{ }^{-}$. This work presents, for the first time, a rapid, low-cost way to detect doxycycline using test paper. The latter is more convenient and faster than other methods mentioned in the literature and can be observed by the naked eyes. This sensor can also detect $\mathrm{MnO}_{4}{ }^{-}$with a lower LOD among other anions compared with the original $\mathrm{MOF}(\mathrm{Eu})$. The proposed hybrid material in this work could have wider applications in the field of sensors.

\section{Conflicts of interest}

There are no conflicts to declare.

\section{Acknowledgements}

This work was supported by the National Natural Science Foundation of China (21371103).

\section{Notes and references}

1 P. J. Ramesh, K. Basavaiah and N. Rajendraprasad, Acta Pharm., 2010, 60, 445-454.

2 M. Y. Xue, L. L. Zhang, Z. H. Zhan, M. B. Zou, Y. Huang and S. L. Zhao, Talanta, 2016, 150, 324-330.

3 K. Smith and J. J. Leyden, Clin. Ther., 2015, 27, 1329-1342.

4 D. Vega, L. Agüí, A. González-Cortés, P. Yáñez-Sedeño and J. M. Pingarrón, Anal. Bioanal. Chem., 2007, 389, 951-958.

5 S. H. Li, J. P. Li, Q. Y. Lin and X. P. Wei, Analyst, 2015, 140, 4702-4707.

6 Y. S. Kim, J. H. Kim, I. A. Kim, S. J. Lee, J. S. Jurng and M. B. Gu, Biosens. Bioelectron., 2010, 26, 1644-1649.

7 Y. L. Tang, J. C. Zhang, J. H. Liu, I. Gapparov, S. Wang, Y. W. Dong, H. J. Su and T. W. Tan, Anal. Methods, 2017, 9, 1133-1140.
8 M. Granados, M. Encabo, R. Compano and M. D. Prat, Chromatographia, 2005, 61, 471-477.

9 H. T. Lu, Y. Jiang, H. B. Li, F. Chen and M. H. Wong, Chromatographia, 2004, 60, 113-116.

10 T. Tylová, J. Olšovská, P. Novák and M. Flieger, Chemosphere, 2010, 78, 353-359.

11 T. Charoenraks, S. Palaharn, K. Grudpan, W. Siangproh and O. Chailapakul, Talanta, 2004, 64, 1247-1252.

12 P. Masawat, S. Liawruangrath and S. Upalee, Maejo Int. J. Sci. Technol., 2008, 2, 201-209.

13 W. L. Shi, F. Guo, M. M. Han, S. L. Yuan, W. S. Guan, H. Li, H. Huang, Y. Liu and Z. H. Kang, J. Mater. Chem. B, 2017, 5, 3293-3299.

14 J. P. Song, J. Li, Z. Y. Guo, W. Liu, Q. Ma, F. Feng and C. Dong, RSC Adv., 2017, 7, 12827-12834.

15 J. Tashkhourian, G. Absalan, M. Jafari and S. Zare, Spectrochim. Acta, Part A, 2016, 152, 119-125.

16 J. Y. Liu, G. C. Lv, W. L. Gu, Z. H. Li, A. W. Tang and L. F. Mei, J. Mater. Chem. C, 2017, 5, 5024-5030.

17 R. Zhou, Q. Zhao, K. K. Liu, Y. J. Lu, L. Donga and C. X. Shan, J. Mater. Chem. C, 2017, 5, 1685-1691.

18 J. Tao, P. Zhao and Q. Zeng, J. Mater. Chem. B, 2016, 4, 42584262.

19 C. Li, W. J. Liu, Y. J. Ren, X. B. Sun, W. Pan and J. P. Wang, Sens. Actuators, B, 2017, 240, 941-948.

20 J. Zong, X. L. Yang, A. Trinchi, S. Hardin, I. Cole, Y. H. Zhu, C. Z. Li, T. Muster and G. Wei, Biosens. Bioelectron., 2014, 51, 330-335.

21 L. B. Li, B. Yu and T. Y. You, Biosens. Bioelectron., 2015, 74, 263-269.

22 S. Chandra, D. Laha, A. Pramanik, A. R. Chowdhuri, P. Karmakar and S. K. Sahu, Luminescence, 2016, 31, 81-87.

23 W. J. Lu, Y. Li, R. J. Li, S. M. Shuang, C. Dong and Z. W. Cai, ACS Appl. Mater. Interfaces, 2016, 8, 12976-12984.

24 A. Cayuela, M. L. Soriano and M. Valcárcel, Anal. Chim. Acta, 2013, 804, 246-251.

25 M. Zheng, Z. G. Xie, D. Qu, D. Li, P. Du, X. B. Jing and Z. C. Sun, ACS Appl. Mater. Interfaces, 2013, 5, 13242-13247.

26 R. K. Das and S. Mohapatra, J. Mater. Chem. B, 2017, 5, 21902197.

27 F. Qu, Z. Sun, D. Y. Liu, X. E. Zhao and J. M. You, Microchim. Acta, 2016, 183, 2547-2553.

28 Y. Zhou, H. H. Chen and B. Yan, J. Mater. Chem. A, 2014, 2, 13691-13697.

29 X. Y. Xu and B. Yan, ACS Appl. Mater. Interfaces, 2015, 7, 721729.

30 J. N. Hao and B. Yan, J. Mater. Chem. A, 2014, 2, 18018-18025.

31 Y. Q. Dong, J. H. Cai, Q. Q. Fang, X. You and Y. W. Chi, Anal. Chem., 2016, 88, 1748-1752.

32 X. Y. Xu and B. Yan, J. Mater. Chem. C, 2016, 4, 1543-1549.

33 J. X. Wu and B. Yan, J. Colloid Interface Sci., 2017, 504, 197205.

34 B. Ding, S. X. Liu, Y. Cheng, C. Guo, X. X. Wu, J. H. Guo, Y. Y. Liu and Y. Li, Inorg. Chem., 2016, 55, 4391-4402.

35 M. Bagheri, M. Y. Masoomi and A. Morsali, Sens. Actuators, B, 2017, 243, 353-360. 
36 B. L. Chen, Y. Yang, F. Zapata, G. Lin, G. D. Qian and E. B. Lobkovsky, Adv. Mater., 2007, 19, 1693-1696.

37 Q. Peng, F. J. Hou and C. Q. Jiang, Spectrochim. Acta, Part A, 2006, 65, 62-66.

38 J. Li, J. K. Liu, X. J. Zhu, Q. Peng and C. Q. Jiang, J. Lumin., 2005, 113, 305-313.

39 C. Q. Jiang and N. Zhang, J. Pharm. Biomed. Anal., 2004, 35, 1301-1306.
40 F. L. Zu, F. Y. Yan, Z. J. Bai, J. X. Xu, Y. Y. Wang, Y. C. Huang and X. G. Zhou, Microchim. Acta, 2017, 184, 1899-1914.

41 L. Li, A. R. O. Raji and J. M. Tour, Adv. Mater., 2013, 25, 62986302.

42 L. Zhang, H. D. Liu, H. B. Ruan, Y. Y. Su, R. Hu, L. L. Tian, Z. L. Hu and J. Li, Int. J. Electrochem. Sci., 2016, 11, 1081510826.

43 M. Chen, W. M. Xu, J. Y. Tian, H. Cui, J. X. Zhang, C. S. Liu and M. Du, J. Mater. Chem. C, 2017, 5, 2015-2021. 